\title{
ENGINEERING DEVELOPMENT OF SLURRY BUBBLE COLUMN REACTOR (SBCR) TECHNOLOGY
}

\section{Quarterly Technical Progress Report No.}

For the Period 1 October - 31 December 1996

\section{FINAL}

\author{
Contractor \\ AIR PRODUCTS AND CHEMICALS, INC. \\ 7201 Hamilton Blvd. \\ Allentown, PA 18195-1501 \\ Bernard A. Toseland, Ph.D. \\ Program Manager and Principal Investigator \\ Richard E. Tischer, Ph.D. \\ Contracting Officer's Representative
}
Prepared for the United States Department of Energy Under Cooperative Agreement No. DE-FC22-95PC95051--22 Contract Period 3 April 1995 - 2 April 2000 Government Award -\$797,331 for 3 April 95 - 2 April 96

March 1999 NOTE: THIS DOCUMENT HAS BEEN CLEARED OF PATENTABLE
INFORMATION. 


\title{
ENGINEERING DEVELOPMENT OF SLURRY BUBBLE COLUMN REACTOR (SBCR) TECHOLOGY
}

\author{
Quarterly Technical Progress Report No. \\ for the Period 1 October - 31 December 1996
}

\section{Contract Objectives}

The major technical objectives of this program are threefold: 1) to develop the design tools and a fundamental understanding of the fluid dynamics of a slurry bubble column reactor to maximize reactor productivity, 2) to develop the mathematical reactor design models and gain an understanding of the hydrodynamic fundamentals under industrially relevant process conditions, and 3) to develop an understanding of the hydrodynamics and their interaction with the chemistries occurring in the bubble column reactor. Successful completion of these objectives will permit more efficient usage of the reactor column and tighter design criteria, increase overall reactor efficiency, and ensure a design that leads to stable reactor behavior when scaling up to large diameter reactors.

\section{Summary of Progress}

\section{State of the Art}

A topical report, "Computer Assisted Gamma and X-Ray Tomography:Applications to Multiphase Flow Systems," has been written and submitted to DOE for review. In addition to discussing the usefulness of the technique, this report contains a design of a "poor man's tomograph" for LaPorte.

(Washington University in St. Louis) (Air Products and Chemicals, Inc.)

\section{Task 2: Technique Development}

An understanding of the correlation between the standard deviation of pressure drop fluctuations and the transition between flow ranges was developed by extending the data to two other temperatures at various flow rates and pressures. The data correlated well. As stated in the July-September quarterly, this work could be useful in understanding flow transitions at LaPorte or Kingsport. Researchers at the Universities of Delft and Amsterdam show correlations between holdup and transition point. Thus, a method of measuring transition point in high-pressure columns would be valuable.

(The Ohio State University)

\section{Task 3: Model Development}

A two-dimensional convection-diffusion model for liquid mixing has been developed. This model accounts for variation in the radial and axial direction, and thus is more realistic than the previous one-dimensional model. 
Drift flux theory has been adapted from two-phase flow systems. A good correlation between the drift flux of gas and gas holdup has now been demonstrated for three temperatures, 27, 47 and $78^{\circ} \mathrm{C}$, and four pressures from 1-150 atmospheres.

(The Ohio State University)

\section{Task 4: SBCR Experimental Program}

The effect of pressure and temperature on gas holdup was further studied to yield data for three temperatures and four pressures. The effect of these variables on bubble size distribution was measured. Changes in bubble size distribution were used to explain the effects of the variables.

(The Ohio State University)

Velocity (using CARPT) and holdup measurements (using CT) were completed in a largediameter, 44-cm column. Measurements were made with and without internals using both water and Drakeoil, the organic medium employed at LaPorte. The axial velocity profile trends were similar to those seen in smaller diameter columns. However, some diameter effects were noted for gas holdup.

(Washington University in St. Louis)

\section{Task 6 : Data Processing}

The two-dimensional liquid mixing model, which had been used previously to interpret laboratory tracer data, is now being employed to interpret the tracer runs from the LaPorte reactor.

(Washington University in St. Louis) 


\section{Washington University in St. Louis Research}

The following report from Washington University for the period October-December 1996 is appended below. It contains

Objectives

Summary of Accomplishments

References

Appendix A: Two Dimensional Convection-Diffusion Model for Liquid Mixing in Bubble Columns

Appendix B: Gas Holdup Distribution Measurements by CT in an 18" Column

Appendix C: Velocity and Turbulence Measurements using CARPT in an 18 " Column 


\title{
SLURRY BUBBLE COLUMN HYDRODYNAMICS Seventh Quarterly Report for Contract DOE-FC 2295 PC 95051
}

\author{
Second Year: April 1996 - March 1997
}

\section{October 1 - December 31, 1996}

The main goal of this subcontract from the Department of Energy via Air Products to the Chemical Reaction Engineering Laboratory (CREL) at Washington University is to study the fluid dynamics of slurry bubble columns and address issues related to scale-up. All the targets set for the first year and the objectives for the second year have been listed in the fifth quarterly report. The objectives for the second year are restated below:

1. Complete review of gamma ray tomography and densitometry for obtaining density profiles with emphasis on applications in the LaPorte AFDU reactor.

2. Develop phenomenological models for liquid (slurry) and gas flow pattern and backmixing.

3. Use developed phenomenological models in interpretation of tracer runs at LaPorte.

4. Extend the Computer Aided Radioactive Particle Tracking / Computed Tomography (CARPT/CT) data base.

5. Continue the evaluation of closure schemes for Computational Fluid Dynamic (CFD) modeling. (It should be noted that this objective and objective no. 4 are coupled.)

In this report, we summarize the progress that has been made in accomplishing the above objectives set for the second year.

\section{Tomography}

A review of gamma ray tomography and densitometry, which includes specific suggestions as to how to implement them in the LaPorte AFDU reactor, has been completed. These suggestions are summarized as follows:

i) At present the instrumentation is being used in the LaPorte reactor for the measurement of only the chordal average holdup along the centerline of the reactor. It is recommended that for a given cross section the measurements be obtained along several such chordal positions at a minimum of two angular orientations $\left(90^{\circ}\right.$ apart) with respect to the reactor. Hence, for the reactor of 18 inches in diameter it would be best to have a minimum of 12 chordal measurements in a given crosssection that is scanned. This would allow reconstruction, via Abel transform of the radial gas holdup profile in the column, the knowledge of which allows assessment of the liquid recirculation velocity profiles. 
ii) A dual energy scanning is recommended to assess the holdup distribution of all the three phases in the LaPorte reactor. Besides the existing Cs-137 (0.66 MeV) source, Cobalt-60 (1.17 MeV and 1.33 MeV) is suggested.

iii) A design of a CT system called (Poor Man's Tomograph) suitable for an industrial scale reactor is proposed. This system, relatively simple in construction, can be implemented in the LaPorte reactor and is capable of a spatial resolution of $3.0 \mathrm{~cm} \times 3.0 \mathrm{~cm}$, and does not require too long a period of time for scanning (considering the reactor size).

A topical report on this subject has been completed and is mailed cocurrently with this quarterly report.

\section{Liquid and Gas Phenomenological Models}

We are ahead of schedule in developing phenomenological models for characterization of liquid (slurry) and gas flow pattern and backmixing.

\section{A. Liquid}

A one dimensional phenomenological model, derived based on CARPT/CT observations, and its governing equations were presented in the $3 \mathrm{rd}$ and 5 th quarterly reports. This model is based on experimentally observed single cell liquid circulation flow pattern. Hence, the bubble column is divided axially into three sections, a middle region and two end zones where the liquid turns around. For simplicity, the end zones are assumed to be perfectly mixed. In the middle region liquid mixing is described by taking into account the recirculation of the liquid. This is done by dividing this region into two sections: one with liquid flowing up in the middle or core section and another with liquid flowing down in the annulus between the core and the walls. The flow within each of these sections is assumed to be fully developed. It is assumed that the upflow and downflow liquid streams communicate via an exchange coefficient. In addition, there is axial dispersion in each liquid region caused by turbulence generated by the bubbles (Degaleesan et al., 1996).

In addition, a higher level phenomenological model (two dimensional convectiondiffusion model) for liquid mixing, which accounts for the variation in the radial direction as well as in the axial direction, has been completed. Appendix A outlines this model and its governing equations (Page 5-8).

\section{B. Gas}

The first level phenomenological gas phase model has been completed and was reported in the 5th quarterly report. It is based on the same physical picture as the 
liquid models. Besides the four regions described above for the liquid (liquid upflow region, liquid downflow region, mixing zone of the liquid at the inlet, and mixing zone of the liquid at the outlet), the gas phase is divided into: large bubble upflow region, small bubble upflow region, small bubble downflow region, distribution region for the gas phase at the inlet, disengagement region for the gas phase at the outlet. Due to the shear between the upflow and downflow of small bubbles and the liquid itself, it is assumed that interactions exist between the small bubbles in the two flow regions (upflow and downflow regions), as well as between the liquid in these two flow regions. These interactions are described via exchange coefficients. In addition, the exchange coefficient between the small and large bubbles is also defined in the model. This allows for the coalescence and break-up of the bubbles to be accounted for (Wang et. al., 1996).

\section{Implementation of the developed phenomenological models in interpretation of tracer runs at LaPorte}

I. All tracer runs in the LaPorte reactor for both methanol synthesis and dehydration of isobutanol to isobutylene have been interpreted using the axial dispersion model (ADM) as presented in the 4th and 6th quarterly reports. It was shown that the ADM can only fit the observed experimental impulse tracer responses at detector levels the furthest removed from the injection point. However, there was a large variation in effective axial dispersion coefficient determined from the responses at different locations. The type of response with overshoots, observed at locations closer to the injection point, is incompatible with the ADM. This demonstrates that ADM does not describe the physical situation well.

II. The capability of the developed one dimensional liquid mixing phenomenological model to interpret the tracer runs in the LaPorte reactor, has been demonstrated in the 5 th quarterly report. The model can capture the observed responses at all detector locations. Using this model to interpret all the tracer runs in LaPorte reactor is part of future work (Degaleesan et al., 1996).

III. The developed two-dimensional liquid mixing model has been successfully applied to interpret tracer data obtained by Myers et al. (1986). Appendix A (Page 5-8) outlines the model and demonstrates its implementation to Myers et al. Tracer data. Model implementation to interpret LaPorte tracer data is in progress. Using this model to interpret all the tracer runs in LaPorte reactor is also part of future work.

\section{CARPT/CT Data Base Extension}

Work continues, as mentioned in the monthly reports, to gather data in a larger diameter $(44 \mathrm{~cm}(18 "))$ column without and with internals using both air-water and air drakeoil systems. 
Appendix B provides some results on gas holdup distribution measurements by CT in an $44.0 \mathrm{~cm}$ (18") column, without internals, for both air-water and air-drakeoil systems. It was found that gas holdup is almost symmetric, increases slightly with increase in axial distance, is lower in air-drakeoil system than in air-water system and is lower in the 18" column than in the 6" column for air-water system (page 915).

Appendix $\mathrm{C}$ shows some results of the velocity measurements by CARPT in the $44.0 \mathrm{~cm}(18 ")$ column using air-water system. The trends for the axial velocity profile at different gas velocities are similar to those obtained in smaller column diameters, indicating that there is no significantly different behavior of the overall liquid flow pattern with scale (page 16-17).

Detailed data processing and analysis for these experiments are in progress.

\section{CFD Modeling}

The person (Sailesh Kumar), who had the responsibility to evaluate different closure schemes for CFD modeling, has left our group. A new research associate (Shadi Saberi) will takeover in January 1997 to continue this computational efforts.

\section{References}

Degaleesan S. S. Roy, S. B. Kumar, M. P. Dudukovic', "Liquid Mixing Based on Convection and Turbulent Dispersion in Bubble Columns," Chem. Eng. Sci., 51, 10, 1967-1976, (1996).

Degaleesan S., S. B. Kumar, M. P. Dudukovic', B. A. Toseland, B. L. Bhatt, "Progress in Understanding the Fluid Dynamics of Bubble Column Reactors", First Joint Power and Fuels System Contractors Conference, Pittsburgh, July, (1996).

Myers, K. J., M. P. Dudukovic', P. A. Ramachandran, "Modeling of Chum-Turbulent Bubble Columns-I: Liquid Phase Mixing," Chem. Eng. Sci., 42, 2301-2311, (1986).

Wang, Q. S. Roy, M. P. Dudukovic', "A Two-Phase Cross Flow with Recycle for Chum Turbulent Bubble Column Reactors", 5th World Congress of Chemical Engineering, Paper 3ae, San Diego, California, July 14-18, (1996). 


\section{$\underline{\text { Appendix A }}$}

\section{Two Dimensional Convection-Diffusion Model for Liquid Mixing in Bubble Columns}

\section{Model Outline}

A two dimensional convection-diffusion model has been developed to describe liquid phase mixing in bubble columns. The model equations have been derived by considering the fundamental two-fluid model for the local, instantaneous tracer species balance for phase $\mathrm{k}$, as given by the following equation,

$$
\frac{\partial \rho k C k}{\partial t}+\nabla \cdot \rho k C_{k} \vec{u}_{k}=0
$$

with an interfacial jump condition for mass transfer across the interface:

$$
\sum_{k=1}^{2} \rho_{k} C_{k}\left[\vec{u}_{k}-\vec{u}_{k i}\right] \cdot \vec{n}_{k}=0
$$

In the above equation, the phase density, $\rho_{\mathrm{k}}$, can be considered to be constant with time, which represents incompressible flows in bubble columns. Phasic or ensemble averaging of the above equation in an axisymmetric system, for an inert, nonvolatile tracer, yields:

$$
\begin{aligned}
& \frac{\partial}{\partial t}\left(\rho_{k} \varepsilon_{k}\left\langle C_{k}\right\rangle^{x}+\right. \frac{\partial}{\partial z} \rho_{k}\left(\varepsilon_{k}\left\langle u_{z, k}\right\rangle^{x}\left\langle C_{k}\right\rangle^{x}+\varepsilon_{k}\left\langle u_{z, k}^{\prime} C^{\prime}\right\rangle_{k}^{x}\right) \\
&+\frac{1}{r} \frac{\partial}{\partial r} r \rho_{k}\left(\varepsilon_{k}\left\langle u_{r, k}\right\rangle^{x}\left\langle C_{k}\right\rangle^{x}+\varepsilon_{k}\left\langle u_{r, k}^{\prime} C_{k}^{\prime}\right\rangle^{x}\right)= \\
&\left\langle\rho_{k} C_{k}\left(\vec{u}_{k}-\vec{u}_{k i}\right) . \nabla X_{k}\right\rangle
\end{aligned}
$$

where \langle\rangle$^{x}$ represents phasic averaging. The right hand side of Eqn. 3 represents the term due to mass transfer across the interface, where $\mathrm{X}_{\mathrm{k}}$ is the phase function. For the present situation, for a non-volatile liquid tracer, this term will be set to 0 . Since the model is primarily concerned with the liquid phase, the index $\mathrm{k}=l$, denoting the liquid phase, will be dropped. In addition, in order to simplify notation, all symbols denoting averaging will also be dropped. 
The cross-correlation terms between the fluctuating velocity and tracer concentration are closed using a standard gradient diffusion model, as

$$
\begin{aligned}
& \left\langle u_{z}^{\prime} C^{\prime}\right\rangle^{x}=-D_{z z} \frac{\partial C}{\partial z} \\
& \left\langle u_{r}^{\prime} C^{\prime}\right\rangle^{x}=-D_{r r} \frac{\partial C}{\partial r}
\end{aligned}
$$

where $D_{z z}$ and $D_{\text {rr }}$ are the axial and radial turbulent eddy diffusivities, respectively. Therefore, the final form of the model equation is:

$$
\frac{\partial(\varepsilon C)}{\partial t}+\frac{\partial}{\partial z}\left(\varepsilon u_{z} C\right)+\frac{1}{r} \frac{\partial}{\partial r}\left(r \varepsilon u_{r} C\right)=\frac{1}{r} \frac{\partial}{\partial r}\left[r \varepsilon D_{r r} \frac{\partial C}{\partial r}\right]+\frac{\partial}{\partial z}\left[\varepsilon D_{z z} \frac{\partial C}{\partial z}\right]
$$

In the above equation, CARPT (Computer Automated Radioactive Particle Tracking) data for the time averaged liquid velocities, $u_{r}$ and $u_{z}$, and turbulent diffusivities, $\mathrm{D}_{\mathrm{rr}}$ and $\mathrm{D}_{\mathrm{zz}}$, along with CT (Computed Tomography) data for the time averaged liquid holdup profile are used as input parameters for the phase averaged fluid dynamic variables. Thereby the model can be solved to simulate the liquid tracer distribution in the column.

\section{Results}

The model equation is numerically solved using the finite volume scheme (Patankar, 1983). An implicit scheme in time, with upwind scheme for the convection term and central differencing for the diffusion term is used. The domain is axially divided into three parts: a distributor zone at the bottom, a fully developed region where the radial liquid velocities are negligible and are assumed to be zero, and a disengagement zone at the top where liquid turns around. Standard boundary conditions are used with zero flux at the wall and at the center of the column. For the case with continuous flow of liquid through the column, a zero gradient is assumed at the outlet with injection of tracer at the inlet.

The test case considered is the tracer data of Myers et al. (1986), whose experiments were conducted in an air-water system in a column of $19 \mathrm{~cm}$ internal diameter, with a superficial gas velocity of $10 \mathrm{~cm} / \mathrm{s}$ and liquid velocity of $1 \mathrm{~cm} / \mathrm{s}$. CARPT and CT experiments were performed under identical conditions to obtain the input hydrodynamic parameters for the system. Results are shown in Figures Al, A2 and A3 for the time averaged axial liquid velocity, liquid holdup profile and turbulent eddy diffusivities, respectively. Using these results as input, the model has been used to predict the tracer response of the given system, shown in Figure A4. 
The comparison between the two dimensional model prediction and the experimental tracer response curve from Myers et al. (1986) suggests that the model prediction provides a good representation of the experimental data. Therefore, using a fundamentally based model with experimental data for the fluid dynamic parameters, the model is indeed able to capture the overall mixing in the system as described by the tracer RTD (residence time distribution).

\section{Future Work}

The model is currently being applied to interpret the radioactive tracer data from the AFDU (Alternate Fuels Development Unit) reactor during methanol synthesis. This requires estimation of the input parameters of the model. Since there are no CARPT/CT data under these conditions preliminary scaleup strategies are being developed to evaluate the model parameters. More details on this, along with the results will be presented in the next report.

\section{Notation}

C Tracer concentration, $\mathrm{mol} / \mathrm{cc}$

$\mathrm{D}_{\mathrm{rr}}, \mathrm{D}_{\mathrm{zz}} \quad$ Radial and Axial Turbulent Eddv Diffusivities, $\mathrm{cm}^{2} / \mathrm{s}$

$\vec{n} \quad$ Normal vector to the interface

$\vec{u} \quad$ Eulerian phase velocity vector, $\mathrm{cm} / \mathrm{s}$

$\mathrm{X} \quad$ Phase function

\section{Greek}

$\varepsilon \quad$ ensemble averaged phase fraction or holdup

$\rho$ phase density, gm/cc

\section{Subscripts}

$\begin{array}{ll}\mathrm{k} & \text { phase } \\ \mathrm{i} & \text { interface } \\ \mathrm{r} & \text { radial direction } \\ \mathrm{z} & \text { axial direction }\end{array}$




\section{References}

Patankar, S. V., Numerical Heat Transfer and Fluid Flow, McGraw-Hill, New York, 1980.

Myers, K. J., Dudukovic', M. P. and Ramachandran, P. A., Modeling of churnturbulent bubble columns - I: Liquid phase mixing. Chem. Engng. Sci. 42, 23012311, 1986.

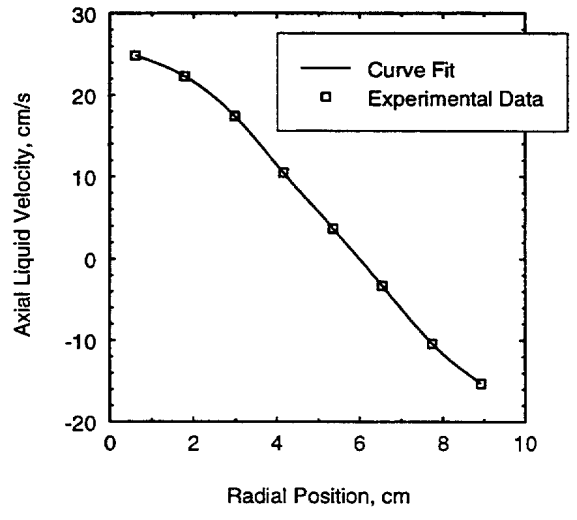

Figure A1: Time Averaged Axial Liquid Velocity

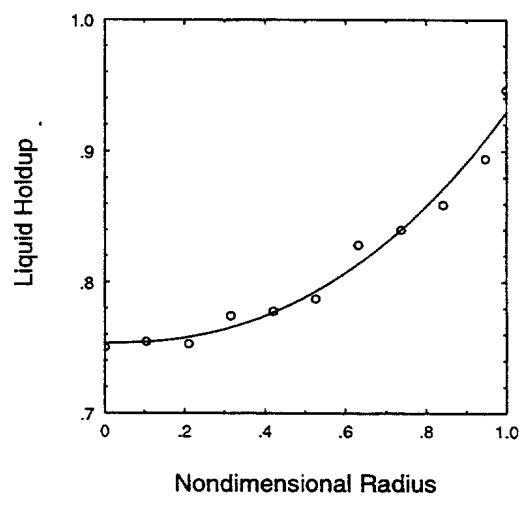

Figure A2: Time Averaged Liquid Holdup 


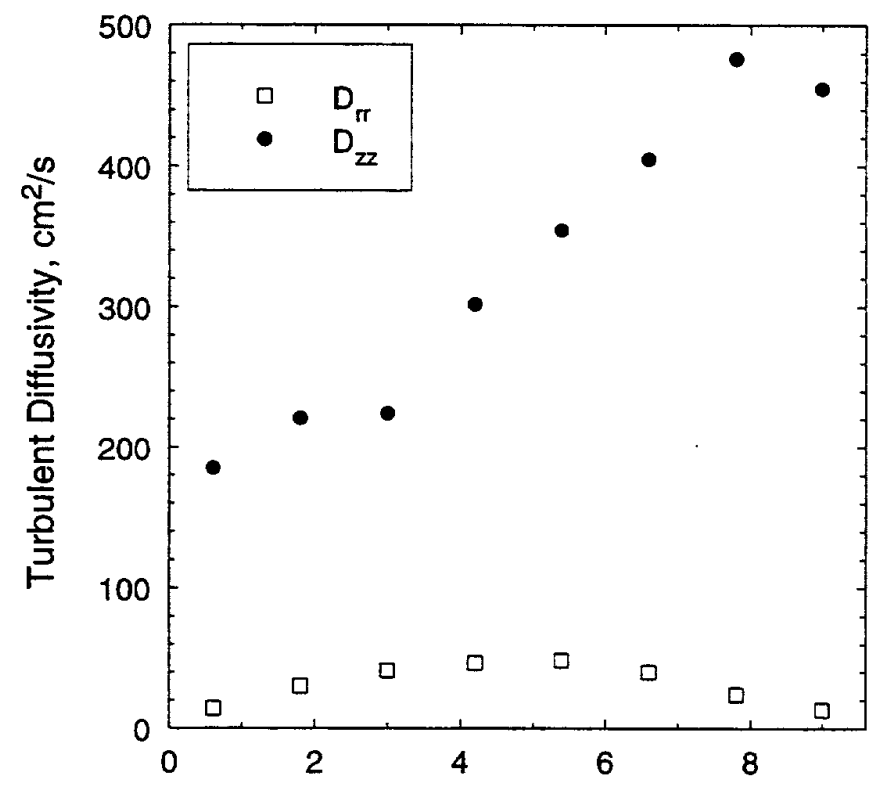

Radial Position, cm

Figure A3: Average Turbulent Eddy Diffusivities

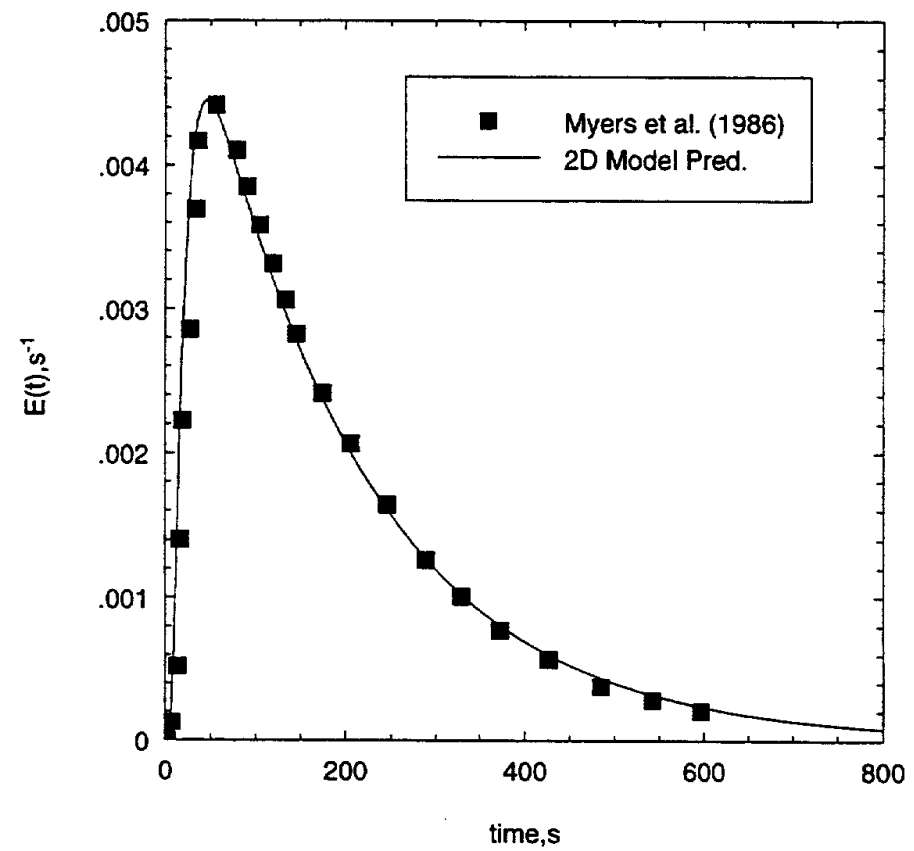

Figure A4: Comparison of Experimental Tracer Response with 2D CDM Prediction 


\section{Appendix B}

\section{Gas Holdup Distribution Measurements by CT in an 18" Column}

\section{Outline of Experiments}

Gas holdup is an important parameter in the design and performance calculations for bubble column reactors. Many studies have been reported on this subject. However, most studies were limited to the measurements of gas holdup in small bubble columns (less than 12" in diameter), with the air-water system. Very few studies have been reported for large bubble columns, with more viscous liquids. Only recently, the whole cross-sectional gas holdup distribution in bubble columns has been obtained by Computer Tomography (CT) scans (Kumar et al, 1995). These results were also reported only for up to a 12" diameter column with an air-water system (Kumar, 1995). In our current study, gas holdup was measured in an 18" column with both an air-water and an air-drakeoil (Drakeol ${ }^{\circledR} 10$, Van Waters \& Rogers Inc.) system using CT scans. The 18" column is shown in Figure B1. The column is made of Plexiglas with a diameter of 18 inches and a height of 8 feet. The distributor used in this study is a perforated plate with the hole diameter of $0.7 \mathrm{~mm}$ and open area of $0.1 \%$. The details of the CT facility can be found in Kumar (1995). In this study, eleven $\mathrm{NaI}$ detectors were used to get statistically better results and 80 views were chosen for each cross-sectional scan. The superficial gas velocities of 2,5 , and $10 \mathrm{~cm} / \mathrm{s}$ were used. Current limitations in our air supply did not allow us to go higher. This will be remedied in the future. For each superficial gas velocity, CT scans were conducted at four different axial levels, $51 \mathrm{~cm}, 89 \mathrm{~cm}, 132 \mathrm{~cm}$ and $170 \mathrm{~cm}$ from the distributor. Below are some preliminary results of the gas holdup distribution measurements.

\section{Results}

\subsection{Cross sectional gas holdup distribution}

By CT scans, the whole cross-sectional gas holdup can be obtained by reconstruction. Figure B2 shows the cross-sectional gas holdup for air-water and air-drakeoil system at $5 \mathrm{~cm} / \mathrm{s}$ superficial gas velocity. One can see from the plots that gas holdup distributions for both systems are almost symmetric, with the high gas holdup in the center and low gas holdup near the wall.

\subsection{The effects of axial distance}

Figure B3 shows the radial gas holdup profiles obtained by azimuthal averaging of the data at different axial levels for both air-water and air-drakeoil system. It was found that the gas holdup slightly increases with the increase in axial distance from the distributor. However, there is a "jump" near the free surface of the column which may be caused by foaming which was observed during the experiments. 


\subsection{The effect of superficial gas velocity}

With the increase in superficial gas velocity gas holdup increases. This is illustrated in Figure B4 for the air-water system. For the air-drakeoil system, the variation is linear, while for the air-water system, it is not.

\subsection{The effects of liquid properties}

The liquids used in this study were water and drakeoil (Drakeol ${ }^{\circledR}$ 10, Van Waters \& Rogers Inc.). The viscosity of water is $1.0 \mathrm{cp}$ at room temperature, while the viscosity of drakeoil is about $35 \mathrm{cp}$. By visual observation, very large bubbles were detected even at low superficial gas velocity of $2 \mathrm{~cm} / \mathrm{s}$ in the air-drakeoil bubble column. At the same gas velocity, small uniform bubbles were observed in the airwater bubble column. Due to the large bubbles formed in drakeoil, the gas holdup is lower than that in water at the same superficial gas velocity. This is clearly evident in Figure B5.

\subsection{Comparison with the results obtained in a 6" bubble column.}

Figure B6 shows the comparison of the azimuthally averaged radial gas holdup distribution in a $6 "$ and an 18" bubble column with air-water system at the same superficial gas velocity of $10 \mathrm{~cm} / \mathrm{s}$. Generally, it is considered that if the column diameter is larger than $15 \mathrm{~cm}$, the column diameter will not affect the gas holdup much. However, there is still a considerable difference in gas holdup for the different columns in Figure 6. A sharp decrease in gas holdup near the wall is observed for the 6" column. The gas holdup in the 18" column is lower than that in the 6" column. Probably, this is due to the larger holes $(0.7 \mathrm{~mm}$ in diameter $)$ in the distributor used in the 18" column, which generates larger bubbles and leads to lower gas holdup. Since the hole diameter was $0.3 \mathrm{~mm}$ for the distributor used in the 6 " column, small bubbles and higher gas holdup are expected.

The wave-like feature of the holdup profile in the center of the column may be due to the artifacts in reconstruction since for large diameter columns our source strength is inadequate. We are working on overcoming the difficulties caused by low intensity of radiation.

\section{Summary}

1) Gas holdup is almost symmetric in an 18" column for both air-water and air-drakeoil system.

2) Gas holdup increases slightly with increase in axial distance from the distributor.

3) Gas holdup in air-drakeoil system is lower than that in air-water system due to the formation of large bubbles in the former case. 
4) Compared to gas holdup in a 6" column, gas holdup in the 18" column is lower and there is little wall effect on gas holdup.

\section{References:}

1. Kumar, B. S., Moslemian, D., and Dudukovic', M. P., 1995, "A Gamma Ray Tomographic Scanner for Imaging Void Fraction Distribution in Bubble Columns," Flow Meas. Instr., Vol. 6, No. 1, pp. 61-73.

2. Kumar, B. S., 1994, Computer Tomographic Measurements of Void Fraction and Modeling of the Flow in Bubble Columns, Ph. D. Thesis, Florida Atlantic University, Boca Raton, FL. 


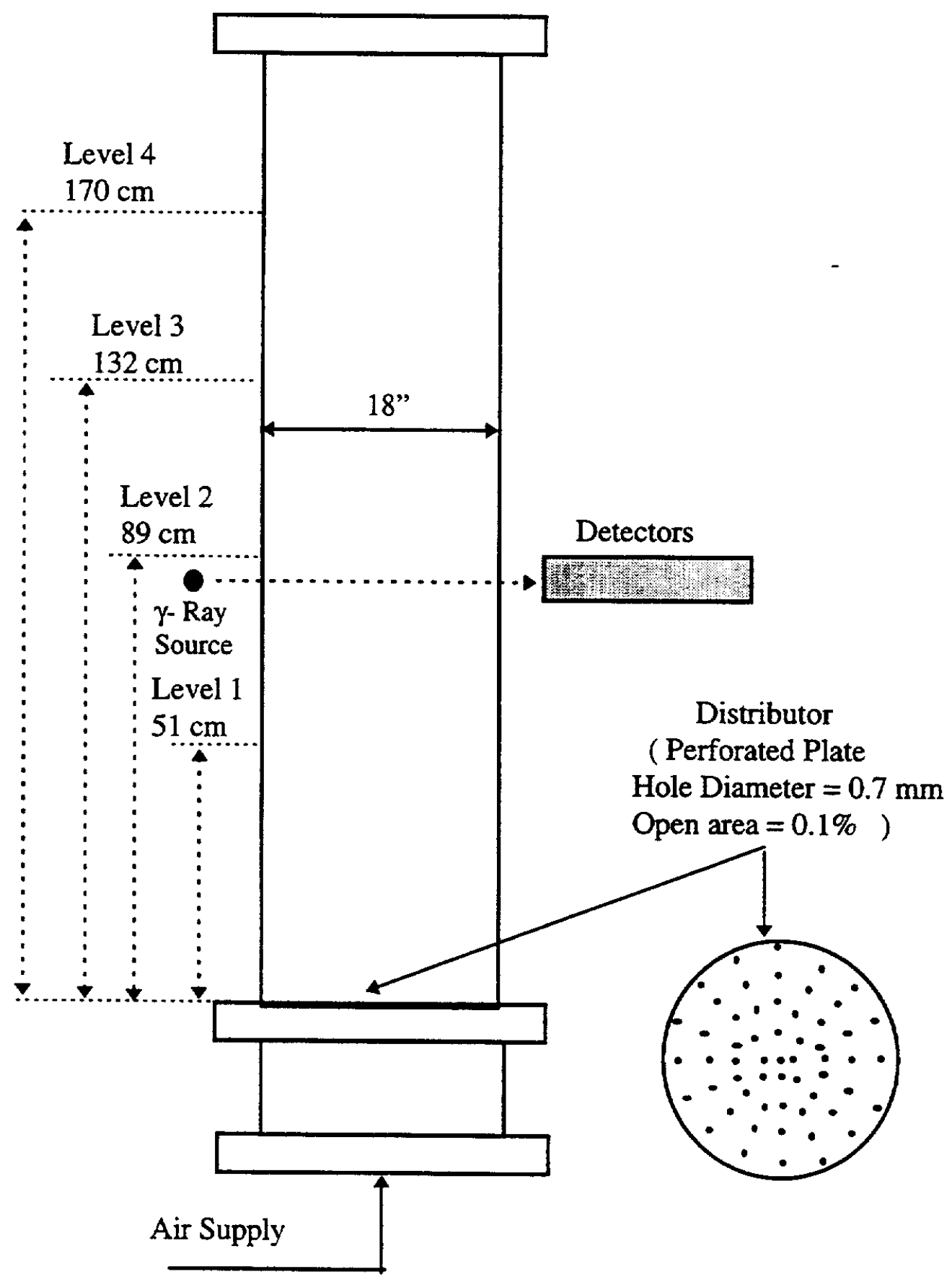

Figure B1. Experiment Setup for the 18" Column CT Scans 


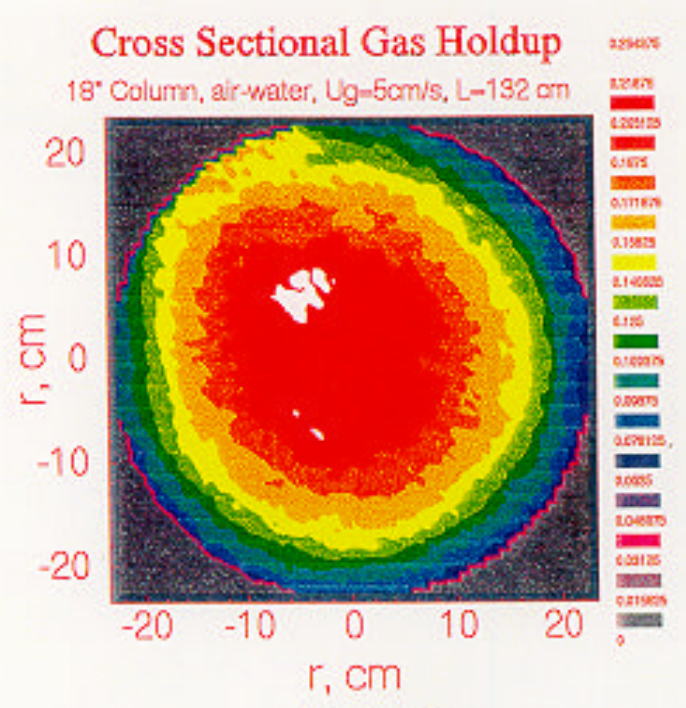

(a) Air-Water

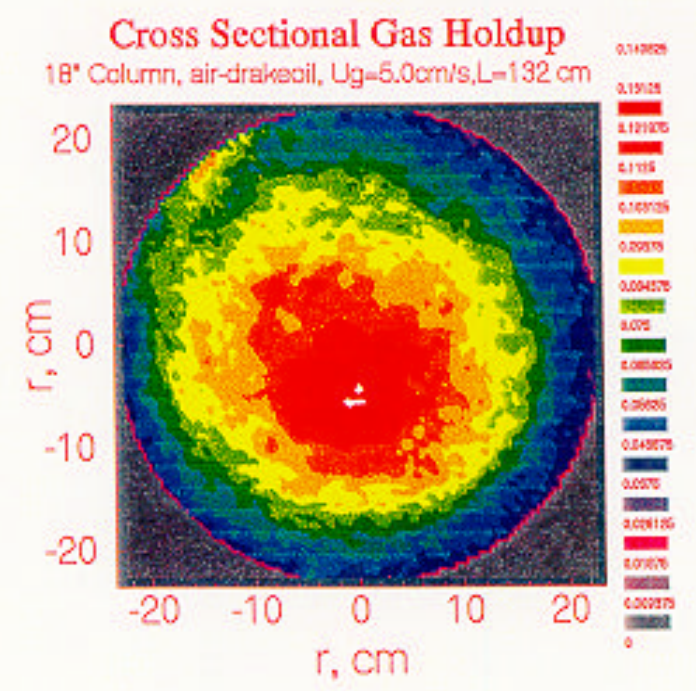

(b) Air-Drakeoil

Figure B2. Cross Sectional gas Holdup Distribution for Air-Water and Air-Drakeoil System 


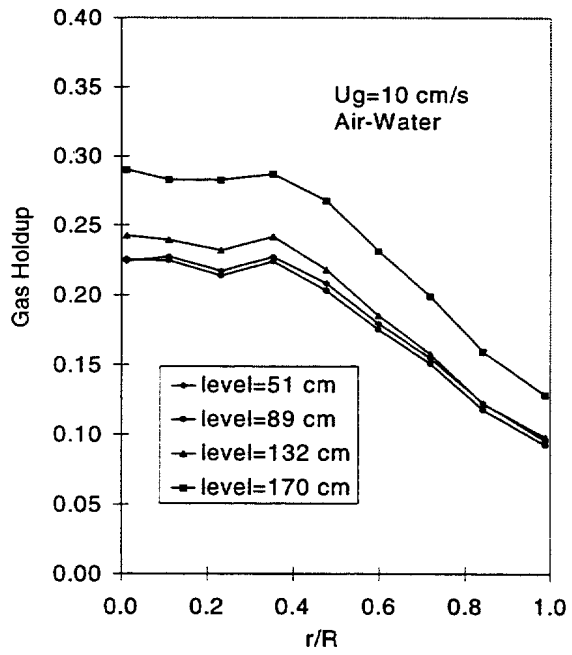

(a) Air-Water



(b) Air-Drakeoil

Figure B3. Gas Holdup at Different Axial Levels

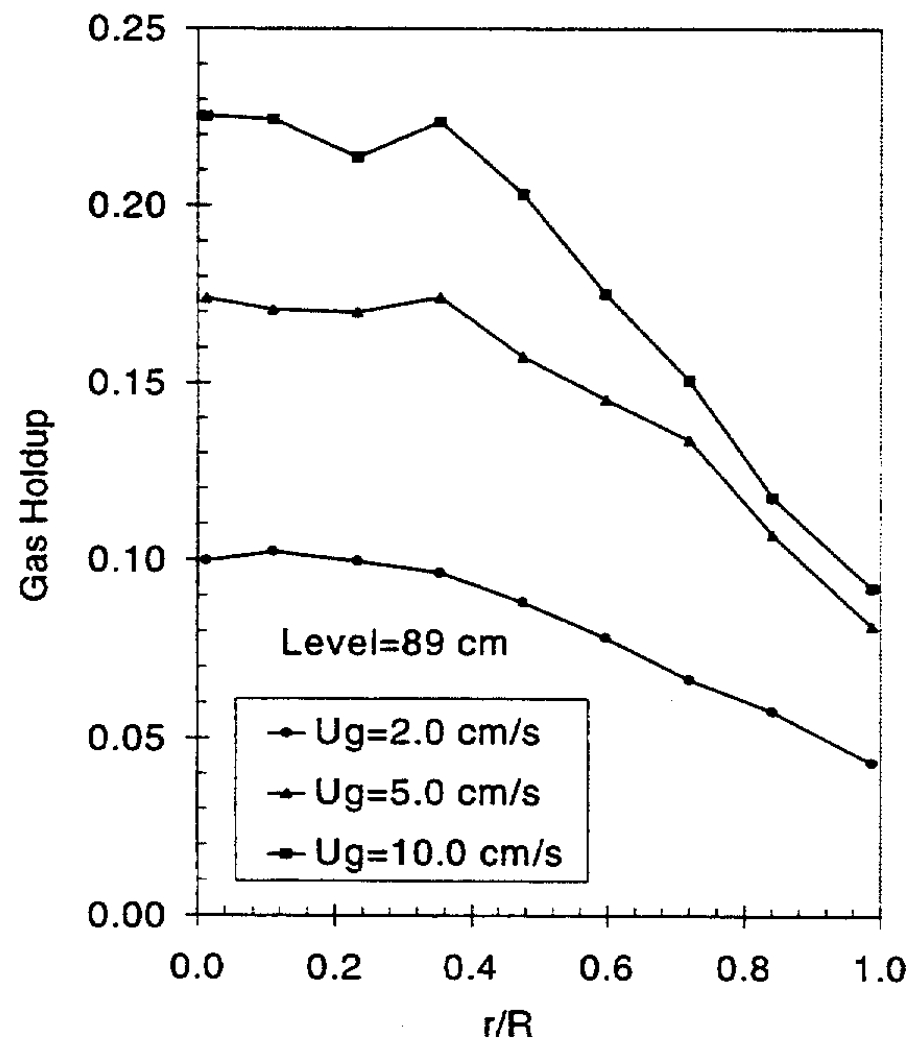

Figure B4. Gas Holdup at Different Superficial Gas Velocities for Air-Water System 


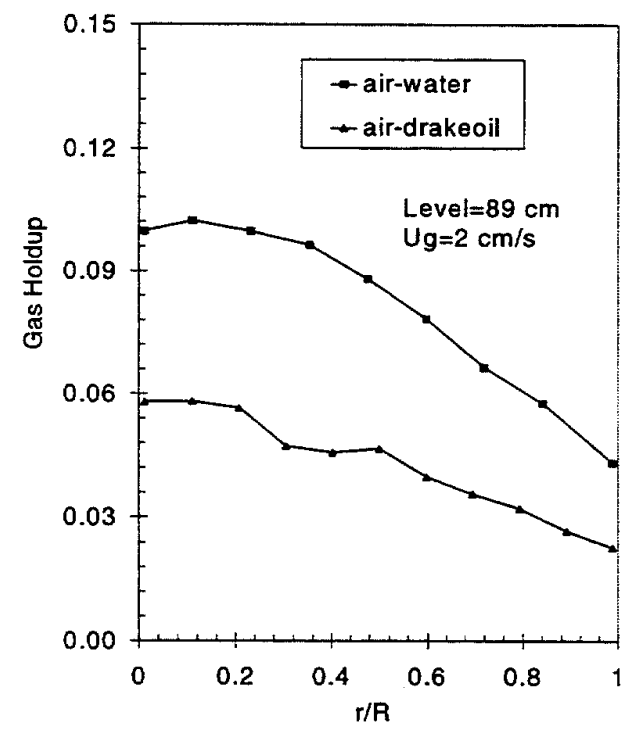

Figure B5. Gas Holdup for Different Liquids

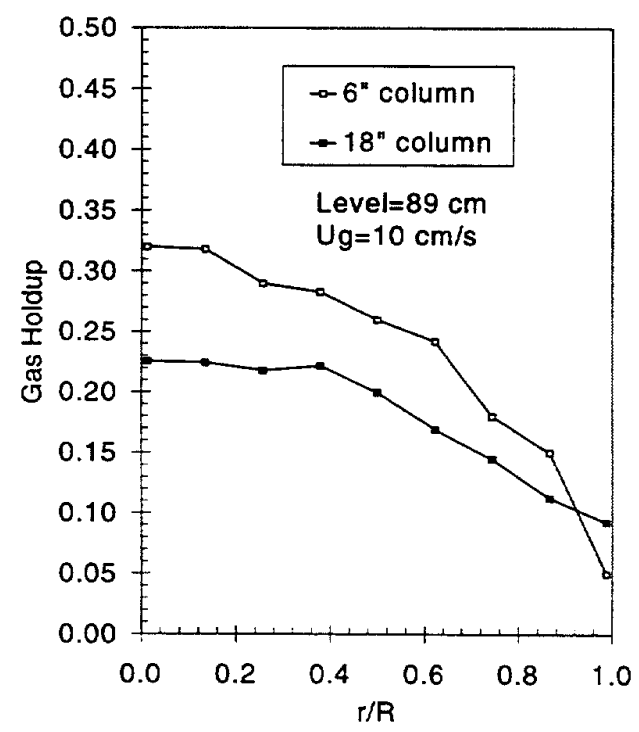

Column

Figure B6. Comparison of Gas Holdup in a 6" Column and an 18"

$0.1 \%$

$0.05)$

(18" column: Hole size $=0.7 \mathrm{~mm}$ in diameter, open area $=$ 5 " column: Hole size $=0.3 \mathrm{~mm}$ in diameter, open area $=$ 


\section{$\underline{\text { Appendix C }}$}

\section{Velocity and Turbulence Measurements using CARPT in an 18" Column}

\section{Experimental Outline}

CARPT (Computer Automated Radioactive Particle Tracking) experiments in an airwater system were conducted in a column of internal diameter $44.0 \mathrm{~cm}$. A perforated plate distributor was used with a pore size of $0.7 \mathrm{~mm}$ and a corresponding open area of $0.1 \%$. Experiments were conducted at three superficial gas velocities that represented different flow regimes in air-water systems, $2 \mathrm{~cm} / \mathrm{s}$ (homogeneous bubbly flow regime), $5 \mathrm{~cm} / \mathrm{s}$ (transition regime) and $10 \mathrm{~cm} / \mathrm{s}$ (heterogeneous churn-turbulent regime). For all the experiments the length to diameter ratio was maintained at about 4.5.

Due to large size of the column, the experiments were conducted for an extensively long period of time in order to obtain good statistics. Wavelet based filtering was performed to remove the white noise in the data due to the statistical fluctuation of the gamma radiation.

\section{Results}

Experimental results show that for all three superficial gas velocities there exists a single circulation cell spanning the length of the column. These results are similar to CARPT results for smaller diameter columns, indicating that there is no radically different behavior of the overall flow pattern with scale. Flow regime transition is also similar to the smaller columns and conforms to the flow regime maps in the literature for air-water systems. Time averaged one dimensional velocity profiles are shown in Figure C1. This shows an increase of circulation velocity with superficial gas velocity, which is expected.

\section{Future Work}

Turbulence parameters are currently being evaluated. Using the data bank for the fluid dynamic parameters generated for air-water systems in different column sizes, attempts will be made to develop preliminary scale-up rules for some of these parameters which can then be used in the phenomenological modeling of bubble column reactors. 


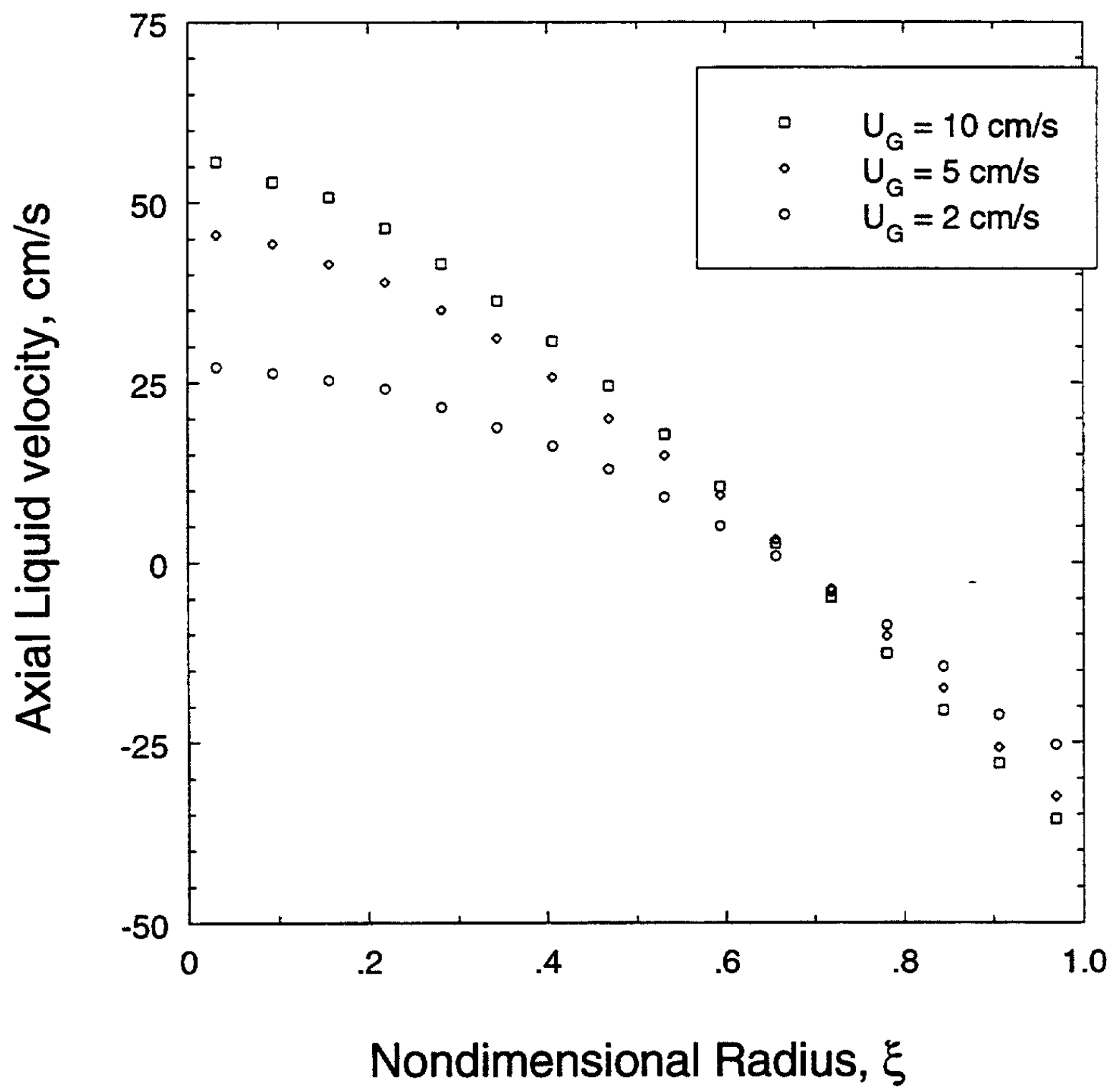

Figure C1: Effect of Superficial Gas Velocity on Time Averaged Axial Liquid Velocity 


\section{The Ohio State University Research}

The following report for the period October -December 1996 contains these brief chapters:

1. Pressure and Temperature Effects on Gas Holdup (Task 4)

2. Regime Transitions (Task 2)

3.References 
INTRINSIC FLOW BEHAVIOR IN A SLURRY BUBBLE COLUMN UNDER HIGH-PRESSURE AND HIGH-TEMPERATURE CONDITIONS

(Quarterly Report)

(Reporting Period: October 1 to December 31, 1996)

\author{
Liang-Shih Fan \\ DEPARTMENT OF CHEMICAL ENGINEERING \\ THE OHIO STATE UNIVERSITY \\ COLUMBUS, OHIO 43210
}

January 20, 1997

Prepared for Air Products and Chemicals, Inc. 
The past three months of research have been focused on two major areas of bubble column hydrodynamics: (1) pressure and temperature effects on gas holdup and (2) region transition using a sparger as a gas distributor.

\section{Pressure and Temperature Effects on Gas Holdup}

Figure 1 shows the effects of pressure and temperature on gas holdup. As seen, gas holdup increases with pressure for a fixed temperature and gas velocity. The underlying mechanisms for this result can be illustrated in terms of the changes in bubble size and rise velocity (distributions), as well as maximum stable bubble size. Figure 2 shows that the maximum stable bubble size is reduced with increasing pressure at all temperatures. Comparisons of the bubble size probability distributions at different operating pressures are given in Figure 3, expressed in terms of histograms, where the most important range of bubble sizes $\left(0.6 \leq d_{b} \leq 4.3 \mathrm{~mm}\right)$ are presented in discrete form to signify the shifting of the dominant bubble size. As the pressure increases from 0.1 to $15.2 \mathrm{MPa}$, the dominant bubble size shifts from 2.5 to $0.6 \mathrm{~mm}$ and the fraction of bubble sizes between 2 and $4 \mathrm{~mm}$ declines by three quarters. In addition, based on the bubble rise characteristic results for a given bubble size $>2 \mathrm{~mm}$, the bubble rise velocity is reduced with increasing pressure. The combination of these effects (smaller bubble size, narrower size distribution, and slower rise velocity) contributes to higher gas holdups in a higher pressure system.

The response of gas holdup to pressure variation depends on temperature. From Figure 1, it can be seen that while at $27^{\circ} \mathrm{C}$ the holdup gradually increases between any two isobars, at $78^{\circ} \mathrm{C}$ the holdup gap between two isobars becomes much narrower at higher pressure compared to that from ambient pressure to $3.5 \mathrm{MPa}$. Figure 4 shows comparisons of the bubble size probability distributions between the operating pressures at $78^{\circ} \mathrm{C}$. It is seen that although the dominant bubble size $(0.5-0.6 \mathrm{~mm})$ is the same for all pressures, the percentage of bubbles larger than $2 \mathrm{~mm}$ is dramatically reduced as the pressure increases from 0.1 to $3.5 \mathrm{MPa}$. The maximum stable bubble size given in Figure 2 also demonstrates a similar trend. This phenomenon can be explained in terms of the effect of physical properties on bubble dynamics.

The effect of temperature on gas holdup for various pressures is shown in Figure 5. Overall, the isobars change from convex to concave as the pressure increases from 0.1 to 15.2 MPa. Based on the trend of these curves, a further increase in pressure would result in narrower gaps between the isobars. This is a result of the continual decrease in surface tension with increasing temperature, while the liquid viscosity is no longer affected by temperature at higher temperatures for all pressures. Note that at ambient pressure, the gas holdup increases by only $2 \%$ when the temperature is increased from 27 to $78^{\circ} \mathrm{C}$; for $15.2 \mathrm{MPa}$, however, the gas holdup increases by $12 \%$. From the mechanistic point of view on the bubble behavior, a higher rate of decrease in liquid viscosity results in a larger decrease in maximum stable bubble size (with increasing bubble breakup rate) and in a smaller initial bubble size. Therefore, the effect of temperature on gas holdup is more significant at higher pressures than at low pressures.

\section{Regime Transition}

In a bubble column, the regime transition is a function of the physical properties of gas and liquid phases and of the design of the system, including gas distributor, column shape, and column 
diameter. The demarcation between dispersed bubble regime and churn-turbulent regime corresponds to the bubble coalescing behavior in the formation of large bubbles and/or bubble swarms. These large or swarm bubbles will induce axial pressure fluctuations that are different from those generated by smaller or uniform bubbles in the dispersed bubble regime. In order to verify this point, an air-water system was operated under ambient conditions in a transparent column (101.6 $\mathrm{mm}$ in diameter). A porous plate was used as the distributor. The gas holdup was obtained by

$$
\varepsilon_{\mathrm{g}}=\frac{\mathrm{L}_{\mathrm{s}}-\mathrm{L}_{\mathrm{f}}}{\mathrm{L}_{\mathrm{s}}}
$$

where $\mathrm{L}_{\mathrm{s}}$ and $\mathrm{L}_{\mathrm{f}}$ are the static and bubbling bed heights, respectively. Figure 6 shows the changes in gas holdup and standard deviation of pressure fluctuations with gas velocity. As noted from Lin et al. (1995), the points of the change of slope, $d$ (holdup)/d( $\left.U_{g}\right)$, correspond to the change of the regimes, i.e., dispersed bubble, churn-turbulent, and turbulent regimes. By closely comparing these two curves, it is found that the points at which there is a change of slope, $\mathrm{d}(\mathrm{stdv}.) / \mathrm{d}\left(\mathrm{U}_{\mathrm{g}}\right)$, correspond well to the points in the holdup versus gas velocity where the regime transition occurs. Therefore, it is reasonable to use the standard deviation of pressure fluctuations to identify the regime transition.

Figure 7 shows the relationship between standard deviation of pressure fluctuation and gas velocity in bubble columns at various pressures and temperatures. From this figure, it is seen that the standard deviation of pressure fluctuation decreases with increasing pressure. This is very reasonable because at a given gas velocity, as the pressure increases, the average bubble size becomes smaller. A smaller bubble transfers less momentum as it rises and thus causes less turbulence in the liquid phase. A smaller turbulence corresponds to a smaller pressure fluctuation across the transducer as the bubbles rise. The standard deviation increases with increasing gas velocity, because at higher gas velocities, bubble clustering and bubble coalescence and breakup occur, causing increased turbulence in the column due to the wakes generated by the large bubbles. Also, the response of gas standard deviation with pressure varies under different temperatures. Figure 7 shows that the standard deviation gradually increases between two isobars at $27^{\circ} \mathrm{C}$, while at $78^{\circ} \mathrm{C}$, the gap in standard deviation between two isobars becomes narrower from ambient pressure to $3.5 \mathrm{Mpa}$.

Furthermore, the drift flux theory is used to identify the regime transition. Darton and Harrison (1975) modified Wallis' (1969) drift flux theory for two-phase flow systems by substituting the relative velocity between the gas and liquid phases $\left(\mathrm{U}_{\mathrm{g}} / \varepsilon_{\mathrm{g}}-\mathrm{U}_{\mathrm{l}} / \varepsilon_{\mathrm{l}}\right)$ for the single-phase velocity in the original equation. The resulting equation, for a two-phase system, is

$$
\mathrm{j}_{\mathrm{gl}}=\left[\left(1-\varepsilon_{\mathrm{g}}\right) / \varepsilon_{1}\right]\left(\mathrm{U}_{\mathrm{g}} \varepsilon_{1}-\mathrm{U}_{1} \varepsilon_{\mathrm{g}}\right)
$$

Our system is a liquid-batch system $\left(\mathrm{U}_{1}=0 \mathrm{~cm} / \mathrm{s}\right)$. Therefore, Eq. 2 can be simplified to

$$
\mathrm{j}_{\mathrm{gl}}=\left(1-\varepsilon_{\mathrm{g}}\right) \mathrm{U}_{\mathrm{g}}
$$

Figure 8 shows the relationship between the drift flux of gas and gas holdup in bubble columns at various pressures and temperatures. It can be seen that the lower portion of the graph corresponds to the dispersed bubble (homogeneous) regime, where the drift flux varies linearly with gas holdup. As the curves become non-linear, the flow changes into the churn-turbulent 
(heterogeneous) regime. At a given gas holdup, the drift flux decreases with pressure due to the smaller bubble size and slower bubble rise velocity in a high-pressure system.

Based on the above analysis, the transition velocity $\left(\mathrm{U}_{\mathrm{g}, \text { tran }}\right)$ varies with pressure and temperature, as shown in Figure 9; both pressure and temperature have positive effects on the transition velocity, which means that increasing pressure or temperature delays the regime transition from either the holdup or gas velocity point of view. However, the effect of pressure on the transition velocity at lower temperature is more significant than that at high temperature. For example, when pressure increases from 0.1 to $15.2 \mathrm{MPa}$, the transition velocity increases two times at $27^{\circ} \mathrm{C}$, but only 1.4 times at $78^{\circ} \mathrm{C}$.

\section{References}

Darton, R. C. and D. Harrison, "Gas and Liquid Holdup in Three-Phase Fluidization," Chem. Eng. Sci., 30, 581 (1975).

Lin, T.-J. and L.-S. Fan, "Characteristics of High Pressure Liquid-Solid Fluidization," AIChE J., in press (1997).

Wallis G. B., “One Dimensional Two-Phase Flow,” McGraw Hill, New York (1969).
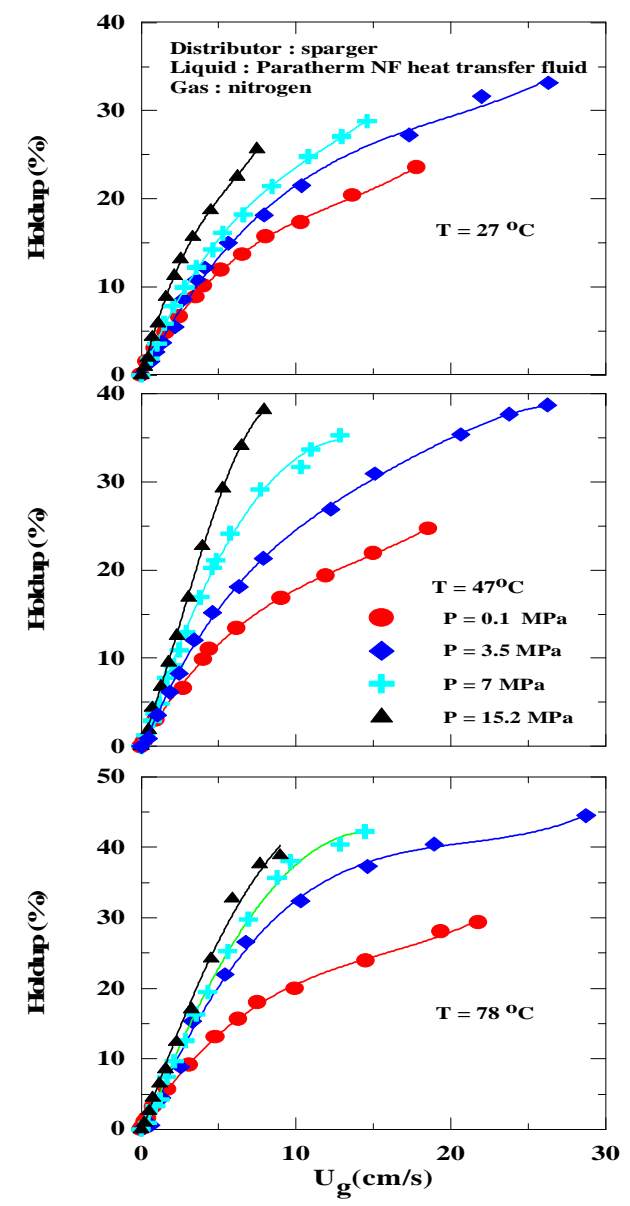

Figure 1 - Pressure Effect on Gas Holdup at 27, 47 and $78^{\circ} \mathrm{C}$ 


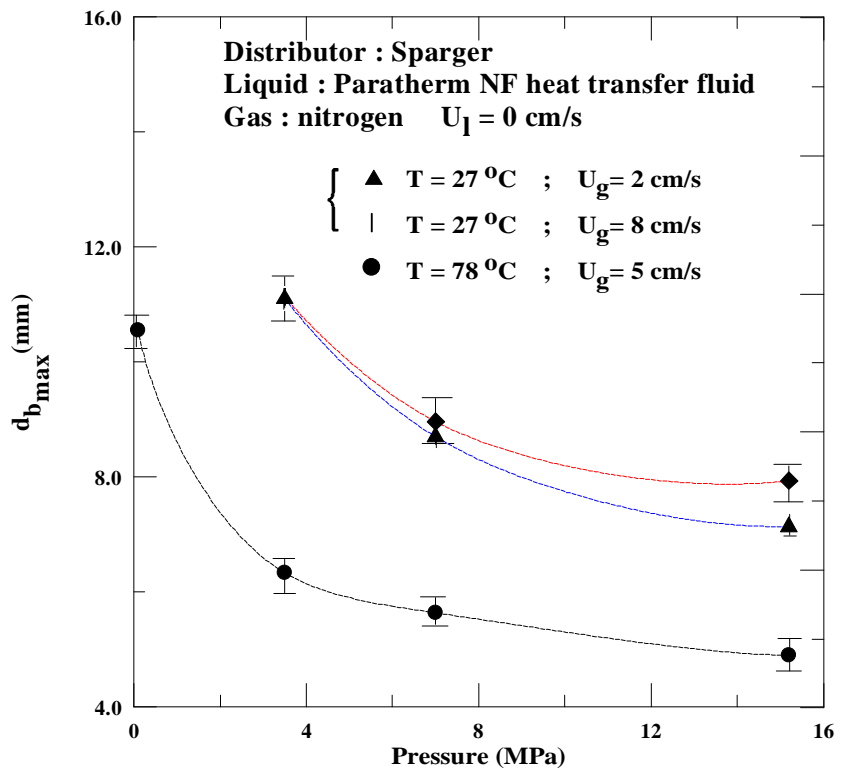

Figure 2 - Pressure Effect on Maximum Stable Bubble Size at Different Temperatures
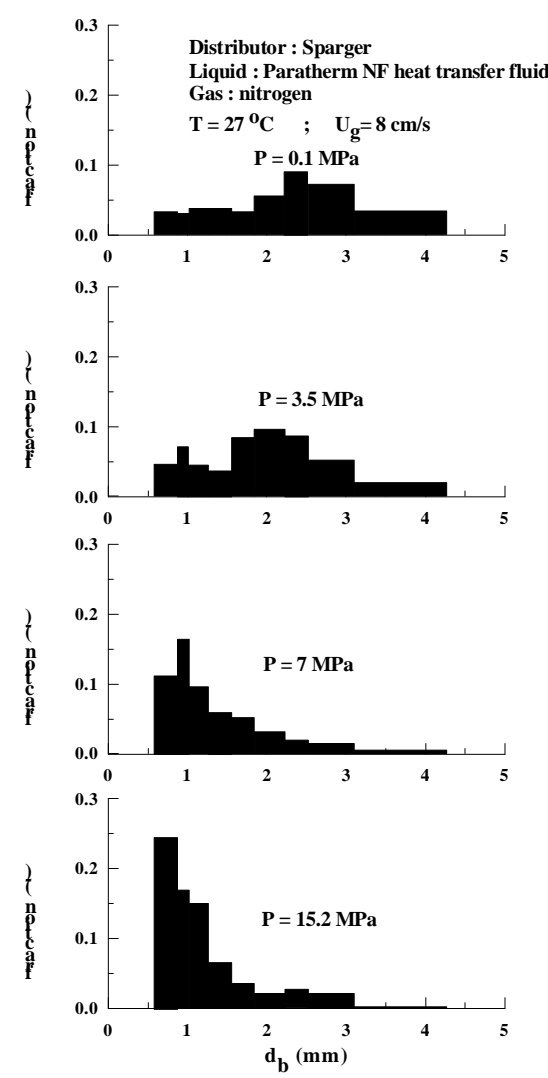

Figure 3 - Pressure Effect on Bubble Size Distribution at $27^{\circ} \mathrm{C}$ 

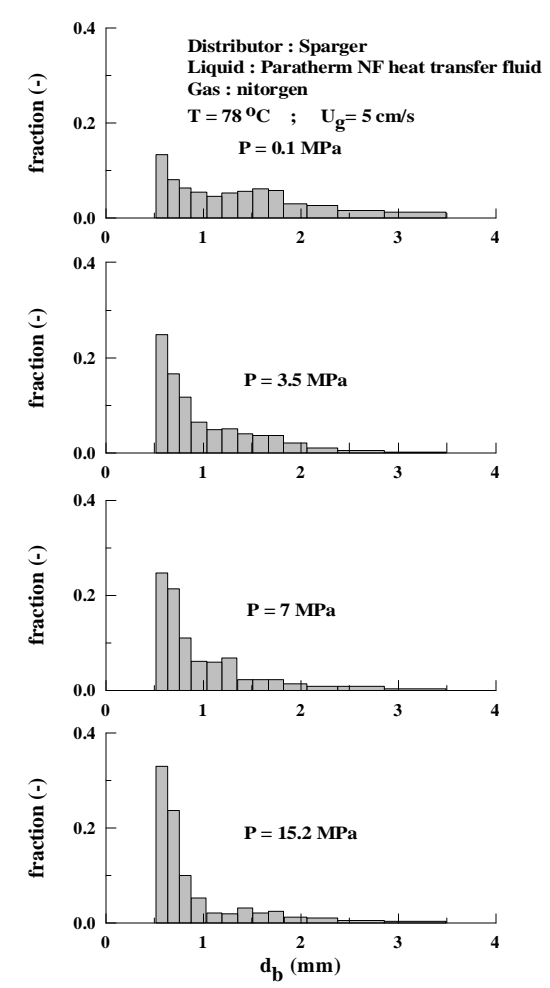

Figure 4 - Pressure Effect on Bubble Size Distribution at $78^{\circ} \mathrm{C}$

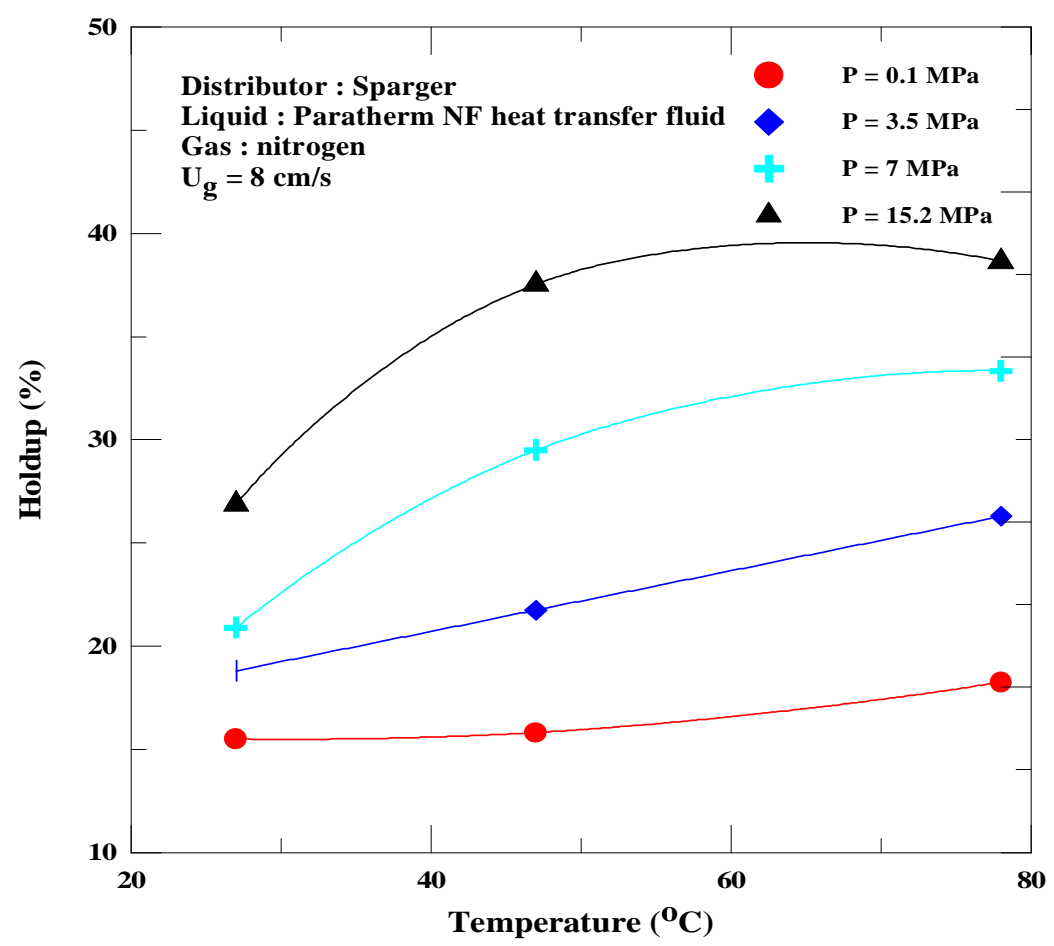

Figure 5 - Temperature Effect on Gas Holdup at Different Pressures 


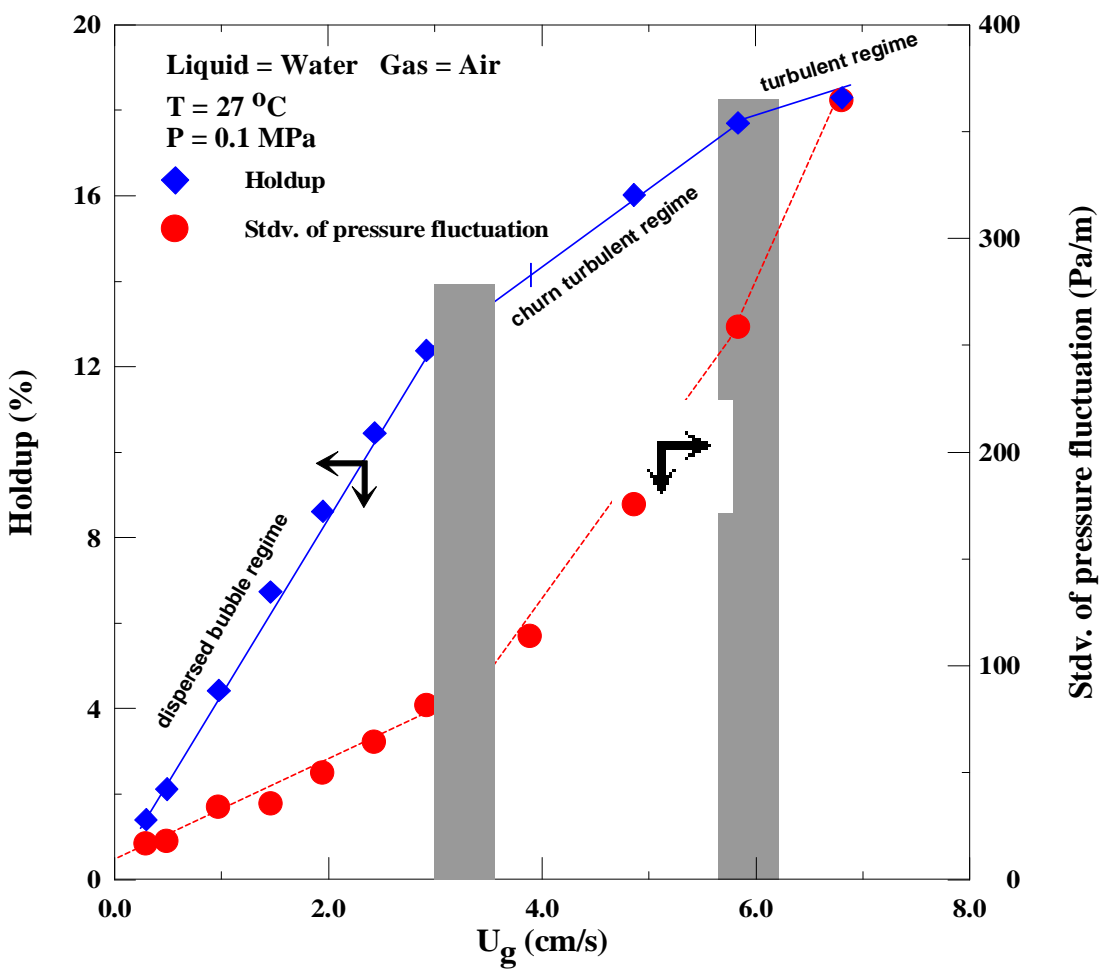

Figure 6 - Changes in Holdup and Standard Deviation of Pressure Fluctuation with Gas Velocity for an Air-Water System at $\mathbf{P}=0.1 \mathrm{MPa}$ and $\mathrm{T}=27^{\circ} \mathrm{C}$ 

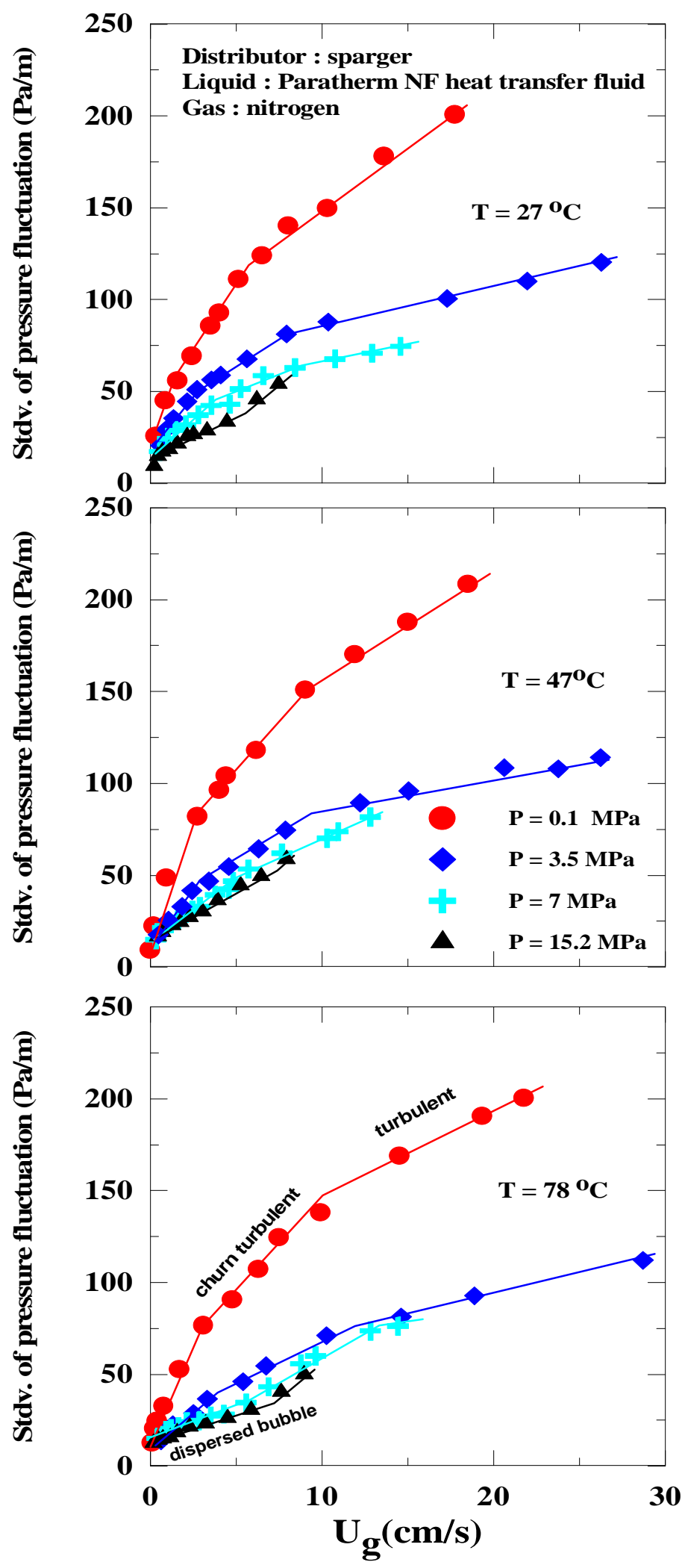

Figure 7 - Relationship Between the Standard Fluctuation Deviation of Pressure Fluctuation and Gas Velocity in Bubble Columns at Various Pressures and Temperatures 

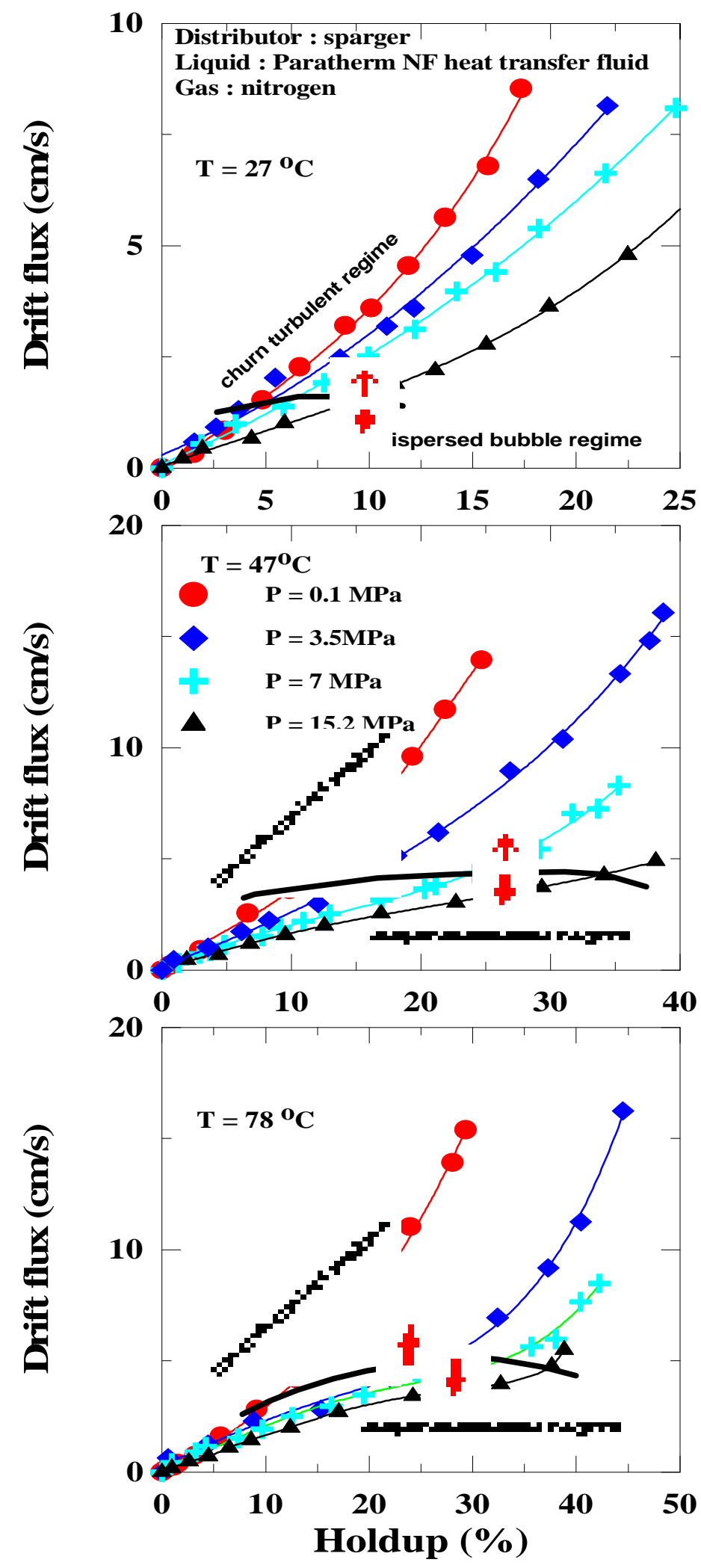

Figure 8 - Relationship Between the Drift Flux of Gas and Gas Holdup in Bubble Columns at Various Pressures and Temperatures 


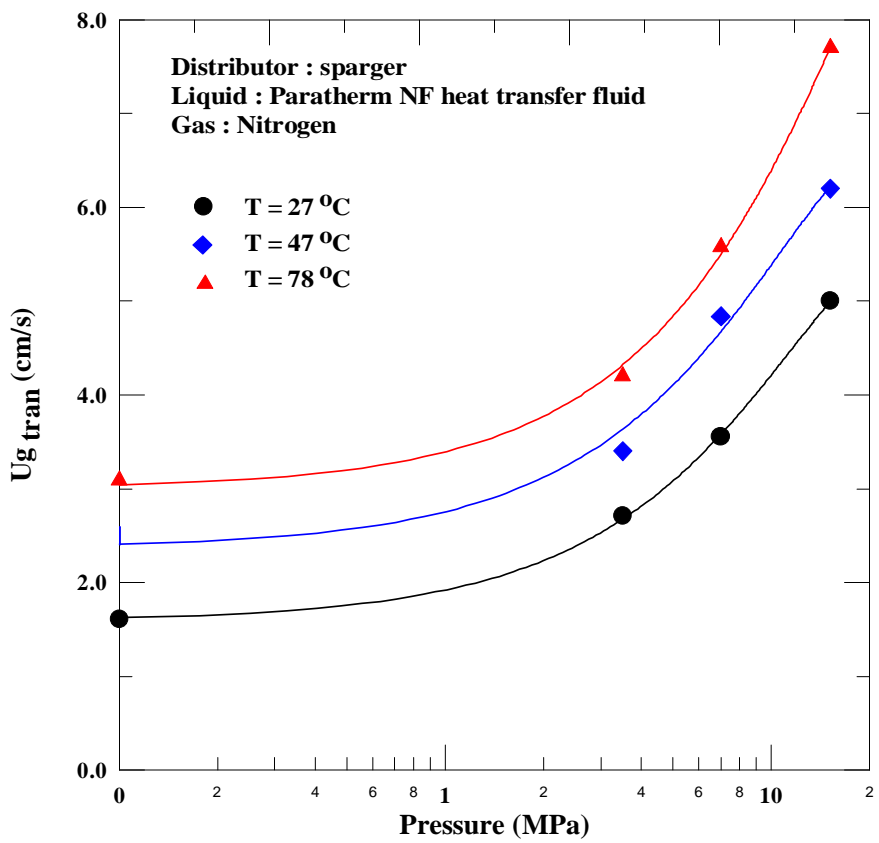

Figure 9 - Variance of $U_{g \text {,trans }}$ with Pressure and Temperature 